\title{
Do etoricoxib and indometacin have similar effects and safety for gouty arthritis? A meta- analysis of randomized controlled trials
}

This article was published in the following Dove Press journal: Journal of Pain Research

\author{
Tzu-Min Lin 1,2,* \\ Jia-En $\mathrm{Chi}^{1,3, *}$ \\ Chi-Ching Chang ${ }^{2,4, *}$ \\ Yi-No Kang'
}

'Center for Evidence-Based Medicine, Department of Education, Taipei Medical University Hospital, Taipei, Taiwan, Republic of China; ${ }^{2}$ Division of Rheumatology, Immunology and Allergy, Department of Internal Medicine, Taipei Medical University Hospital, Taipei, Taiwan, Republic of China; ${ }^{3}$ School of Medicine, College of Medicine, Taipei Medical University, Taipei, Taiwan, Republic of China; ${ }^{4}$ Division of Allergy, Immunology and Rheumatology, Department of Internal Medicine, School of Medicine, College of Medicine, Taipei Medical University, Taipei, Taiwan, Republic of China

*These authors contributed equally to this work
Correspondence: Yi-No Kang Center for Evidence-Based Medicine, Department of Education, Taipei Medical University Hospital, 252, Wu-Hsing Street, Taipei I I0, Taiwan, Republic of China

Email academicnono@gmail.com
Background: Gout, a common medical condition that causes pain, can be treated by painkillers and anti-inflammatories. Indometacin and etoricoxib are two such drugs. However, no synthesized evidence exists comparing etoricoxib with indometacin in treating patients with gout.

Methods: We searched PubMed, Embase, Ovid MEDLINE, Web of Science, ScienceDirect, and the Cochrane Library without restrictions on language or publication date for potential randomized clinical trials comparing etoricoxib with indometacin for gout. The meta-analysis was conducted using a random-effects model.

Results: Search results yielded 313 references from six electronic databases, four of which met the eligibility criteria. These four were randomized clinical trials, and they involved a total of 609 patients with gouty arthritis. No significant differences were observed in pain score change, tenderness, or swelling between etoricoxib and indometacin; the mean differences were -0.05 ( $95 \% \mathrm{CI},-0.21$ to 0.10$),-0.06$ ( $95 \% \mathrm{CI},-0.18$ to 0.05 ), and -0.04 ( $95 \% \mathrm{CI},-0.17$ to 0.09 ). However, the pooled data revealed that significantly fewer overall adverse events occurred in the etoricoxib group $(n=105,33.5 \%)$ than in the indometacin group $(n=130,44.1 \%)$ and the risk ratio was 0.77 (95\% $\mathrm{CI}, 0.62-0.94)$.

Conclusion: Our meta-analysis revealed that etoricoxib and indometacin have similar effects on pain relief. However, etoricoxib has a significantly lower risk of adverse events than does indometacin, especially digestive system-related adverse events.

Keywords: gout, etoricoxib, indometacin

\section{Introduction}

Gout is a common medical problem that mainly affects middle-aged men, ${ }^{1}$ with a peak incidence in the fifth decade of life. ${ }^{2}$ The prevalence of gout increases among postmenopausal women with diuretic-treated hypertension and renal insufficiency. ${ }^{3}$ Risk factors for gout include obesity, alcohol intake, diuretic use, a diet rich in meat, seafood, or high-fructose food or drink intake, and poor kidney function. ${ }^{4-7}$ Furthermore, an increased risk of cardiac disease in patients with gout was observed and this risk is above and beyond that contributed by the traditional risk factors for heart disease. ${ }^{8,9}$ Gouty arthritis not only contributes to heart disease but also directly influences the quality of life. Acute gouty arthritis often peaks within 24 hours of onset with a very painful, warm, tender, and swollen joint, and it commonly affects the joints of the lower extremity, particularly the metatarsophalangeal joint. ${ }^{10,11}$ According to the 2012 American College of Rheumatology Guidelines for Management of Gout, ${ }^{12}$ nonsteroidal anti-inflammatory drugs (NSAIDs), corticosteroids, or oral colchicine 
are appropriate first-line options for the treatment of acute gout and certain combinations can be used for severe or refractory attacks. They suggest the use of the NSAIDs, such as naproxen, indometacin, and sulindac, for the treatment of acute gout. However, nonselective NSAIDs, which inhibit both cyclooxygenase (COX)-1 and COX-2, are associated with dyspepsia and potential gastrointestinal (GI) perforations, ulcers, and bleeding. ${ }^{13,14}$ Etoricoxib, a highly selective COX-2 inhibitor, has demonstrated anti-inflammation, analgesic, and antipyretic properties and reduces the incidence of GI-related adverse events, compared with nonselective NSAIDs. ${ }^{15-18}$ Besides, the cardiovascular safety of COX-2 inhibitor has been revealed. ${ }^{19}$ Indometacin is the most potent inhibitor of nonselective NSAIDs, although a more potent inhibitor of COX-1 than that of COX $-2 .{ }^{20}$ We performed a systemic review and meta-analysis to compare the efficacy and safety of etoricoxib and indometacin in the treatment of acute gout.

\section{Methods}

\section{Search and study selection}

Relevant research articles comparing etoricoxib and indometacin in patients with gouty arthritis were searched by using the following relative terms in PubMed, Embase, Ovid MEDLINE, Web of Science, ScienceDirect, and the Cochrane Library: "gout", "gouty”, "gouty arthritis", "uric arthritis", "arthralgia", "Etoricoxib", and "indometacin”. The systematic literature search using free-text, medical subject headings (MeSH and Emtree), and Boolean algebras was conducted by two authors to identify citation records without language or publication date restrictions from inception till July 19, 2018 (Table S1).

The two authors screened the returned citations imported into EndNote (Version X7) for Microsoft Windows. EndNote systematically removed duplications. The authors completed further categorizations and duplications manually. The inclusion criteria in the title and abstract screening phase were as follows: 1) studies involving patients with gout and 2) studies directly comparing etoricoxib and indometacin. The exclusion criteria in the subsequent full-text screening phase were as follows: 1) studies investigating combined therapy, 2) studies not involving a randomized controlled trial (RCT), and 3) articles not reporting a complete study (conference report and relevant documents). The first author (TML) participated in the screening task in case of any disagreement regarding screening categorization between the two authors.

\section{Outcomes assessment}

This systematic review and meta-analysis conducted outcomes of effects and safety between etoricoxib and indometacin. The outcomes of effects included tenderness, swelling, global assessments, and pain score. There were two parts in global assessments that consisted of patient's assessment and investigator's assessment. The pain score was measured by VAS. The safety outcomes included adverse events that analyzed with subgroup analysis according to systems.

\section{Quality assessment}

This systematic review and meta-analysis assessed the risk of bias by using the appraisal tools of the Risk of Bias Tool of Cochrane. The tool comprises the following items: random sequence generation, allocation concealment, blinding of participants and personnel, blinding of assessment, incomplete outcome data, selective reporting, and other sources of bias. These eight items in the appraisal tool addresses six categories of bias, namely selection bias, performance bias, detection bias, attrition bias, reporting bias, and other bias. Two authors (T-ML and J-EC) individually assessed the included RCTs. The author (Y-NK) participated in the appraisal work in case of any disagreement regarding screening categorization between the two authors.

\section{Data extraction and analysis}

Two authors independently performed data extraction. They not only identified relevant data but also double-checked the meaning of the data and converted the data for appropriate pooling analysis. If the included articles reported mean and standard error (SE) without $\mathrm{SD}$, the authors estimated the $\mathrm{SD}$ on the basis of the included sample size $(\mathrm{SE}=\mathrm{SD} / \sqrt{ } N)$. If the included study reported median values with minimum and maximum only, the authors estimated the mean and SD values from the sample size, median, and range. ${ }^{21}$

Peto ORs were calculated when dichotomous data involved zero cells. Mean differences (MDs) of the original studies pooled in a random-effects model were used to compare continuous variables measured using the same tool and conditions between etoricoxib and indometacin. $I^{2}$ obtained from each meta-analysis was used for estimating the heterogeneity among the included studies. Statistical significance was set at $P<0.05$ for all analyses. $I^{2}$ of the pooled studies was represented using the percentage of total variability across the studies. $I^{2}$ values 25,50 , and $75 \%$ were considered to indicate low, moderate, and high heterogeneity, respectively. ${ }^{22}$ Data were expressed as risk ratios with 
95\% CI, and $I^{2}$ was calculated and presented in a forest plot and analyzed using the RevMan software (Version 5.3) for Microsoft Windows. Small study bias was detected by using funnel plot with Egger's regression intercept. The systematic review and results of meta-analysis are reported according to the PRISMA guidelines. ${ }^{23}$

\section{Results}

\section{Literature search and selection}

The search returned 313 records, of which 13 citations were from PubMed, 99 citations were from Embase, 123 citations were from Ovid MEDLINE, 33 citations were from ScienceDirect, 32 citations were from Web of Science, and 13 citations were from the Cochrane Library. Of these, 85 citations were duplicated. According to the exclusion criteria, 211 citations were excluded after title and abstract screening. In the full-text screening phase, 13 non-RCTs and conference reports were excluded. The literature identification and study selection process are presented in Figure 1.

\section{Characteristics of included studies}

The four RCTs included in this synthesis randomized 609 patients, with 14 patients lost to follow-up. ${ }^{24-27}$ Table 1 lists the study characteristics including trial location, inclusion years, sample size, patients' age, sex, disease classification, and index joint, and loss to follow-up. These studies spanned approximately 15 years from 2002 to 2016 and involved Africa, America, and Asia. Most of the included patients were men. Figure 2 presents the individual quality of the included studies. In summary, the quality of the studies was acceptable, except for the reporting bias item. The four RCTs had a high risk of bias (25\%) in terms of allocation generation, allocation concealment, blinding, and incomplete outcome data. However, the risk of reporting bias was high (Figure S1).

\section{Effect outcomes}

The effects of etoricoxib and indometacin on gouty arthritis are presented in Table 2. In two included studies with 363 patients with acute gouty arthritis, ${ }^{24,25}$ the presented evidence revealed no significant differences in pain score change in days $2-5$ and days $2-8$ between etoricoxib and indometacin and the MDs were $-0.05(95 \% \mathrm{CI},-0.21$ to $0.10 ; P>0.05)$ and -0.05 (95\% CI, -0.20 to $0.10 ; P>0.05$ ) (Figure S2). These two analyses were conducted with low heterogeneity $\left(I^{2}=0 \%\right.$; $P>0.05)$. Three trials reported the effect of the two medications on tenderness. ${ }^{24-26}$ The pooled data of 510 patients revealed no significant difference in tenderness between etoricoxib and indometacin $(\mathrm{MD}=-0.06 ; 95 \% \mathrm{CI},-0.18$ to

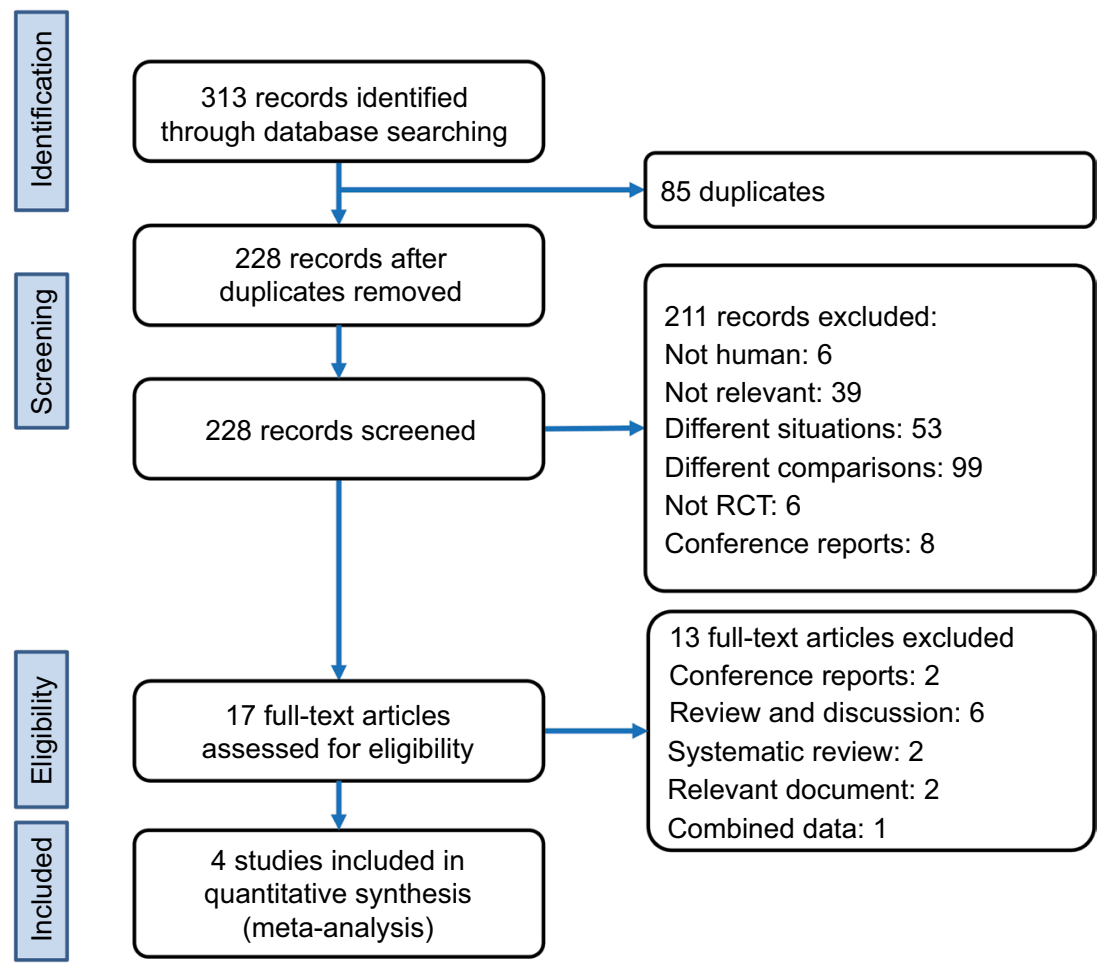

Figure I Flowchart of literature identification and study selection for a systematic review and meta-analysis according to PRISMA guidelines. Abbreviation: RCT, randomized controlled trial. 


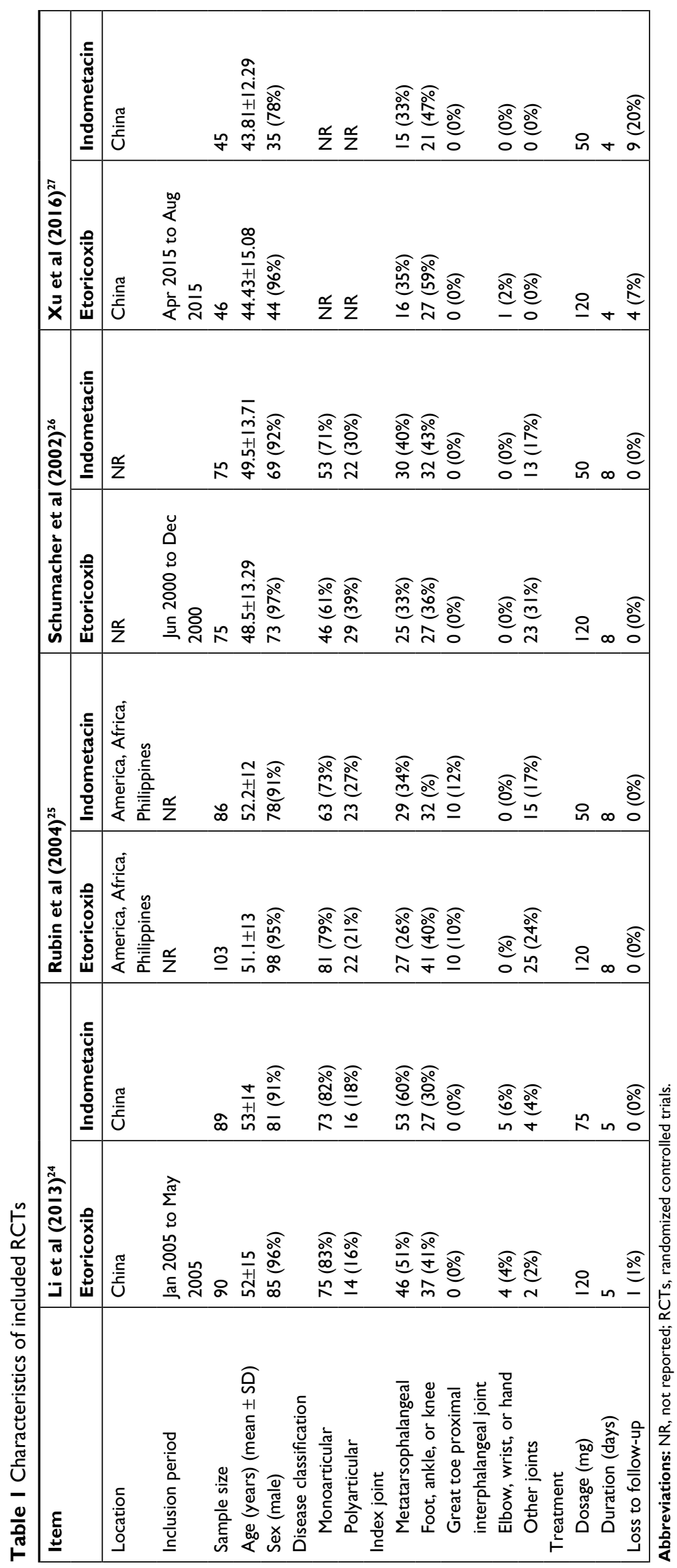




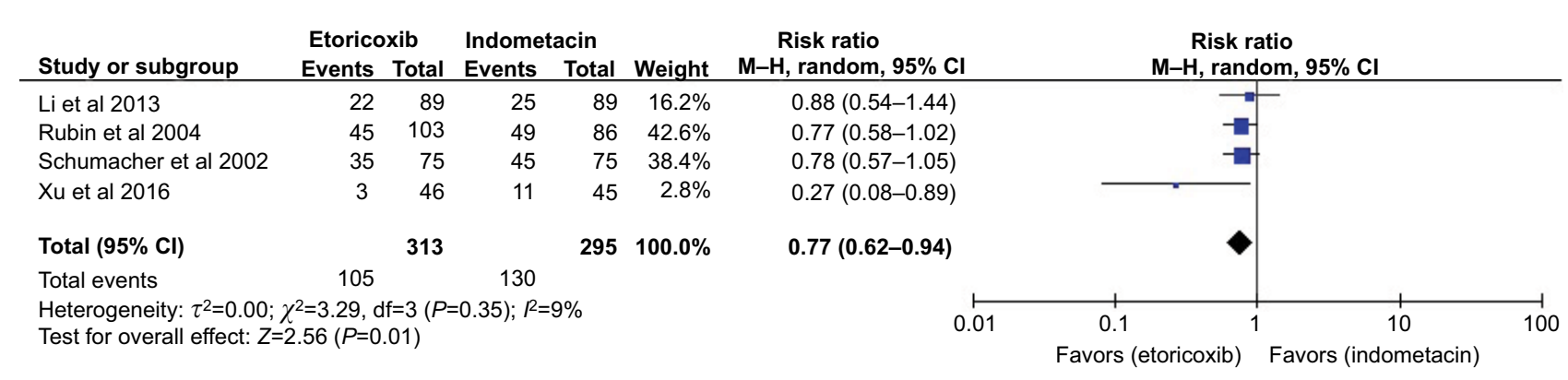

Figure 2 Forest plot of meta-analysis for overall adverse events between etoricoxib and indometacin.

Table 2 Effect outcome summary

\begin{tabular}{|l|l|l|l|l|l|l|}
\hline Outcomes & Studies (n) & Etoricoxib (n) & Indometacin (n) & MD & $\mathbf{9 5 \%} \mathbf{~ C l}$ & $\mathbf{I}^{\mathbf{2}(\%)}$ \\
\hline Pain score change & & & & & \\
$\quad$ Days 2-5 & 2 & 191 & 172 & -0.05 & $-0.21-0.10$ & 0 \\
$\quad$ Days 2-8 & 2 & 191 & 172 & -0.05 & $-0.20-0.10$ & 0 \\
Tenderness & 3 & 265 & 245 & -0.06 & $-0.18-0.05$ & 0 \\
Swelling & 3 & 265 & 245 & -0.04 & $-0.17-0.09$ & 0 \\
Global assessment & & & 243 & -0.09 & $-0.25-0.06$ & 0 \\
$\quad$ Patient's assessment & 3 & 262 & 244 & -0.11 & $-0.22-0.01$ & 0 \\
$\quad$ Investigator's assessment & 3 & 263 & & & \\
\hline
\end{tabular}

Abbreviation: MD, mean difference.

$0.05 ; P>0.05$ ) (Figure $\mathrm{S} 3$ ). Three of the four included RCTs reported information on swelling. ${ }^{24-26}$ The meta-analysis based on data from 510 patients showed no significant difference between etoricoxib and indometacin ( $\mathrm{MD}=-0.04$; $95 \% \mathrm{CI},-0.17$ to $0.09 ; P>0.05$ ) (Figure S4). Moreover, the pooled data of three RCTs with 505 patients revealed no significant difference in the patient's global assessment between the two drugs ( $\mathrm{MD}=-0.09 ; 95 \% \mathrm{CI},-0.25$ to 0.06 ; $P>0.05$ ) (Figure $\mathrm{S} 5)^{24-26}$ and the meta-analysis of three RCTs with 507 patients also indicated no statistical difference in the investigator's global assessment between the drugs (MD $=-0.11 ; 95 \% \mathrm{CI},-0.22$ to $0.01 ; P<0.05)$ (Figure $\mathrm{S} 6) .{ }^{24-26}$ Low heterogeneity $\left(I^{2}=0 \% ; P>0.05\right)$ was found in all the meta-analyses of effect outcomes.

\section{Safety outcomes}

Four RCTs reported adverse events. ${ }^{24-27}$ The pooled data of 608 patients revealed that fewer overall adverse events occurred in the etoricoxib group $(n=105,33.5 \%)$ than in the indometacin group $(\mathrm{n}=130,44.1 \%)$ with significance, and the risk ratio was $0.77(95 \% \mathrm{CI}, 0.62-0.94 ; P<0.05)$ (Figure 2). The heterogeneity of this pooled analysis was also low $\left(I^{2}=9 \% ; P>0.05\right)$. Sensitivity analysis showed that trend of the result was not changed when any included RCT was removed from the meta-analysis (igure S7). The Egger's test $(t=1.523 ; 95 \% \mathrm{CI},-6.211$ to $2.963 ; P=0.267)$ did not detect small study bias in this result (Figure S8).

According to the available data, this systematic review identified adverse events of the digestive system, nervous system, and general symptoms. Data on adverse events of the respiratory system, cardiovascular system, and severe adverse events were insufficient to conduct a meta-analysis. The adverse events of the digestive system include abdominal distention, gastrectasia, diarrhea, stomach upset, stomachache, digestive tract upset, nausea, vomiting, and dry mouth. The nervous system adverse events were somnolence and hand numbness. The general symptoms were dizziness, vertigo, chills, fever, pedal edema, and headache. The pooled data of four RCTs with 608 patients revealed that the etoricoxib group $(\mathrm{n}=19,6.1 \%)$ had fewer digestive system adverse events than the indometacin group $(\mathrm{n}=45,15.3 \%)$, with the Peto OR being 0.37 (95\% CI, 0.22-0.62; $P<0.05$ ) (Figure 3, 2.2.1). ${ }^{24-27}$ Three of the included four RCTs reported information on nervous system adverse events. ${ }^{24,26,27}$ The evidence revealed that the etoricoxib group $(\mathrm{n}=1,0.5 \%)$ had fewer nervous system adverse events than the indometacin group ( $\mathrm{n}=9,4.3 \%$ ), with the Peto OR being 0.19 (95\% CI, 0.06-0.68; $P<0.05$ ) (Figure 3, 2.2.2) ${ }^{24,26,27}$ However, the meta-analysis of the three RCTs with 419 patients indicated no difference in general symptoms between the two groups, 


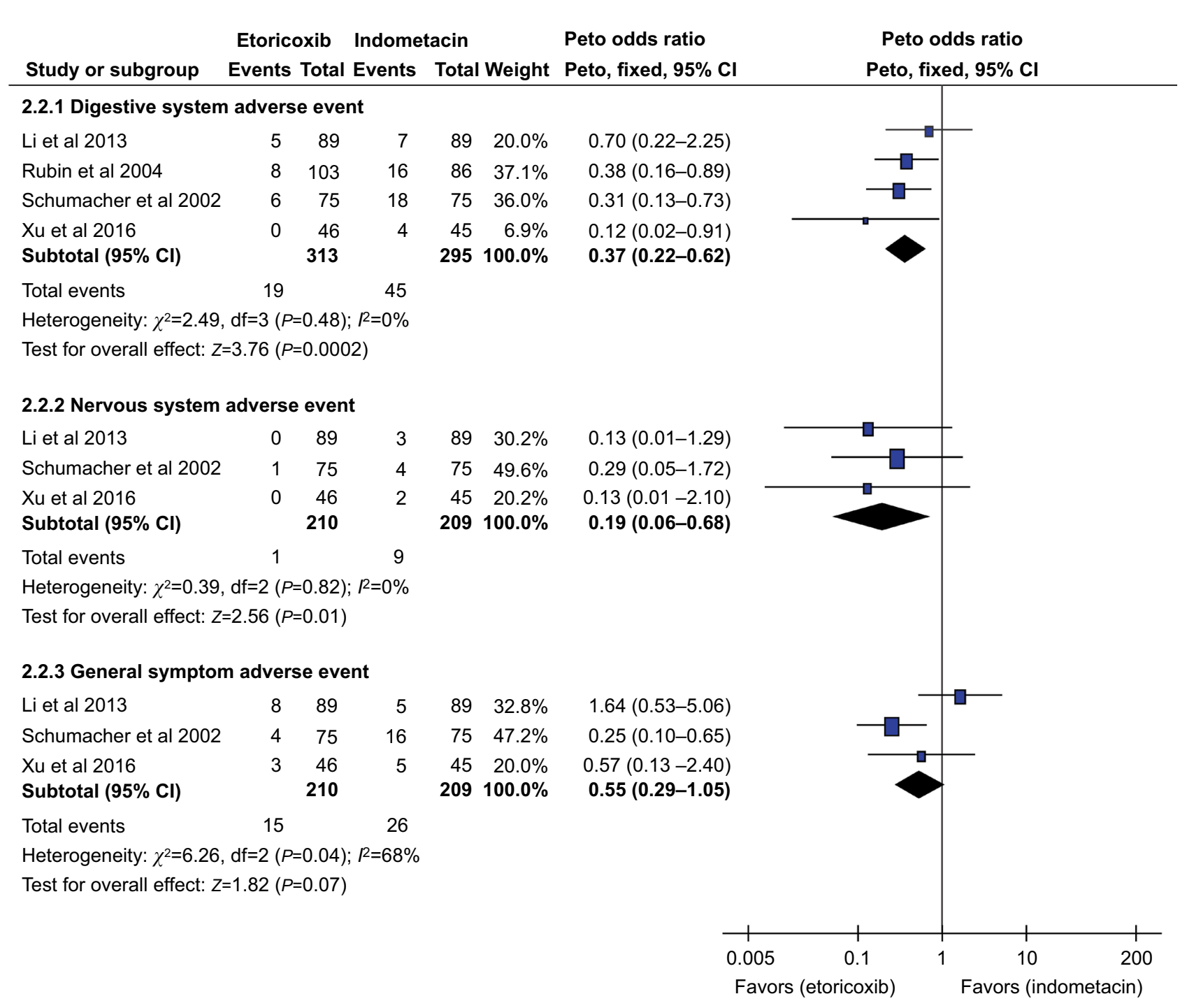

Figure 3 Forest plot of meta-analysis for categorized adverse events between etoricoxib and indometacin.

with the Peto OR being 0.55 (95\% CI, 0.29-1.05; $P>0.05)$

(Figure 3, 2.2.3). ${ }^{24-26}$

\section{Discussion}

\section{Contribution of etoricoxib to gout}

Acute gouty arthritis is the most common form of inflammatory arthritis. Prostaglandins play a major role in the process of inflammatory response. They are derived from arachidonic acid through the action of COX isoenzymes. COX-1 is constitutively expressed in most cells and is responsible for homeostatic functions, which include epithelial cytoprotection, platelet aggregation, and renal blood flow regulation. ${ }^{28}$ COX-2, induced by inflammatory stimuli, is the dominant source of prostaglandins in inflammation. ${ }^{28,29}$ Human data indicate that COX-1-derived prostanoids drive the initial phase of inflammation, whereas COX-2 upregulation occurs several hours later. ${ }^{30-32}$ Both COX-1 and COX-2 are involved in the process of acute inflammation; moreover, our study revealed comparable effects of etoricoxib and indometacin on gouty arthritis.

In the analyzed studies, digestive tract upset was the most common complication in patients under treatment with either etoricoxib or indometacin. NSAID-induced injuries to the GI tract ranging from petechia to ulcers were not rarely observed. They disrupted the mucosa of the GI tract, causing bleeding, perforation, or obstruction. ${ }^{33}$ NSAID-induced ulcerative lesions of the stomach predominantly result from systemic effects associated with the mucosa and topical injury to the mucosa. In systemic effects, COX inhibition was reported to lead to platelet inhibition and prostanoid depletion. ${ }^{33}$ When 
platelets are inhibited, gastric ulcer healing may be influenced through altering the ability of releasing growth factors such as EGF and vascular endothelial growth factor. ${ }^{34,35}$ Hence, inhibition with selective COX-2 inhibitors may be safer in the GI tract and in platelets. ${ }^{36}$ In the RCTs analyzed in this systematic review, ${ }^{24-27}$ the incidence of the adverse events of the digestive system was significantly lower in patients taking etoricoxib than in those taking indometacin, a finding that is consistent with the aforementioned results. Additionally, recent results have revealed that both $\mathrm{COX}$ isozymes may be a source of cytoprotective prostanoids for inhibiting COX-1 and upregulating $\mathrm{COX}-2$ expression, despite the possible existence of subsequent deleterious effects such as gastric hypermotility. ${ }^{37}$ Hence, inhibition of both COX-1 and COX-2 may increase the risk of gastric lesion formation. ${ }^{37}$

PGE2 and PGI2 are the main protective prostaglandins. Inhibiting them by using NSAIDs may decrease the stimulation of the synthesis and secretion of mucus and bicarbonate and reduce mucosal blood flow and epithelial proliferation, resulting in tropical injury of the stomach mucosa, thus making it susceptible to endogenous and exogenous factors such as acid and Helicobacter pylori infection. ${ }^{33}$ In addition, NSAIDs that are weak acids may cause topical damage of the epithelium at the site of the GI mucosa, according to the hypothesis that NSAIDs would compromise the extracellular zwitterionic phospholipid hydrophobic surface barrier of the stomach to luminal acid. ${ }^{38}$

The perfusion of the luminal surface of the stomach is essential for mucosal integrity. ${ }^{33}$ When focal gastric mucosal blood flow decreases, the mucosa becomes more susceptible and NSAID-induced injuries such as hemorrhagic foci and ulceration may occur at the focal ischemic patch. ${ }^{39}$ PGE2 and PGI2 are vasodilators, and inhibiting their synthesis is likely to cause focal ischemia; however, selective COX-2 NSAIDs do not reduce gastric mucosa blood flow. ${ }^{40,41}$ Inhibiting TXA2 production through platelet $\mathrm{COX}-1$ inhibition increases the bleeding tendency when an active GI bleeding site is present. ${ }^{42}$ Most ( $86 \%$ ) of the NSAIDs' GI effects are in the upper GI tract. ${ }^{43}$ One effective strategy for managing NSAID-GI bleeding is proton pump inhibitors (PPIs). The PPI strategy for NSAID-GI risk reduction is that this approach covers the proportion of events occurring only in the upper GI tract ${ }^{44}$ and it can significantly reduce the risk of upper GI bleeding. ${ }^{45}$ Moreover, leukocytes may be one of the factors in the pathogenesis of NSAID-induced gastric ulceration. NSAIDs such as indometacin are potent promoters of leukocytes, particularly neutrophils, and adhere to the vascular endothelium within GI microcirculation, leading to mucosal injury. ${ }^{46,47}$
In the small intestine, topical damage engendered by NSAIDs plays a key role in the pathogenesis of intestinal injury; it could be concluded that the intensity of the intraluminal mucosal injury is related to the duration for which the epithelium has been exposed to these drugs and enterohepatic circulation contributes extensively to this process. ${ }^{33}$

Adverse events in renal function are also noteworthy. Both COX-1 and COX-2 are expressed in the kidneys. Inhibition of the renal prostaglandin E2 can result in the sodium retention and edema and exacerbation of hypertension. Inhibition of prostacyclin expression can reduce renal blood flow and glomerular filtration rate. ${ }^{48}$

\section{Strengths, limitations, and implications for future research}

The present study has more advantages than published systematic reviews and meta-analyses. ${ }^{49,50}$ The advantages of this systematic review and meta-analysis are as follows: 1) a more specific pharmacological comparison was conducted between etoricoxib and indometacin, which are the most potent inhibitors of nonselective NSAIDs; 2) a new RCT was involved; 3) a more meaningful subgroup analysis on complications was conducted; and 4) a modified statistical method of Peto ORs was used when dichotomous data indicated zero cells. Therefore, the present findings may be more reliable than those of previous meta-analyses.

Despite its advantages, the present meta-analysis has some limitations. Although our meta-analysis exhibited low heterogeneity, some limitations may be reflected in the characteristics of the included RCTs. First, the population in the four included RCTs was predominantly male. Therefore, the results of the present meta-analysis may not satisfactorily represent the female population. Second, disease classification and index joint may influence drug effects. However, the present meta-analysis cannot separately access the data according to disease classification and index joint. The present meta-analysis could provide only an overview of the comparison of the effects and safety of etoricoxib and indometacin. Future research must determine the effects and safety of the two drugs by considering different sexes, disease classification, and index joint. A well-designed RCT or meta-analysis of individual patient data may be warranted in the future. Third, PPI is recommended to prevent NSAIDGI bleeding, but the RCTs we included in this systematic review and meta-analysis did not reported any PPI usage. Thus, the combined effect of PPI and the two drugs should be investigated in further trials. Moreover, the present metaanalysis cannot assess publication bias. Because all of the 
outcomes pooled from only four RCTs, this meta-analysis cannot constructed meaningful funnel plots for publication bias assessment. ${ }^{51}$

\section{Conclusion}

From our meta-analysis, we found that etoricoxib has more favorable trend than indometacin in providing pain relief in acute gouty arthritis. Moreover, etoricoxib has a significantly lower risk of adverse events than indometacin, particularly for digestive system adverse effects. The effects of etoricoxib and indometacin among all the medications including interleukin-1 inhibitors, colchicine, and glucocorticoids should be investigated in future studies.

\section{Author contributions}

TML designed the study, identified evidence systematically, critically appraised the included articles, interpreted the result of analysis, and drafted the first version of manuscript. JEC identified evidence systematically, critically appraised the included articles, acquired the data, managed data, and critically reviewed the manuscript. CCC interpreted the result of analysis, critically reviewed the manuscript, and supervised research. YNK proposed the study, analyzed the data, acquired the data, interpreted the result of analysis, and critically revised the manuscript. All authors contributed toward data analysis, drafting and critically revising the paper, gave final approval of the version to be published, and agree to be accountable for all aspects of the work.

\section{Disclosure}

The authors report no conflicts of interest in this work.

\section{References}

1. Kramer HM, Curhan G. The association between gout and nephrolithiasis: the national health and nutrition examination survey III, 1988-1994. Am J Kidney Dis. 2002;40(1):37-42.

2. Harris MD, Siegel LB, Alloway JA. Gout and hyperuricemia. Am Fam Physician. 1999;59(4):925-934.

3. García-Méndez S, Beas-Ixtláhuac E, Hernández-Cuevas C, et al. Female gout: age and duration of the disease determine clinical presentation. J Clin Rheumatol. 2012;18(5):242-245.

4. Choi HK, Atkinson K, Karlson EW, Curhan G. Obesity, weight change, hypertension, diuretic use, and risk of gout in men: the health professionals follow-up study. Arch Intern Med. 2005;165(7) :742-748.

5. Choi HK, Atkinson K, Karlson EW, Willett W, Curhan G. Alcohol intake and risk of incident gout in men: a prospective study. Lancet. 2004;363(9417):1277-1281.

6. Choi HK, Atkinson K, Karlson EW, Willett W, Curhan G. Purine-rich foods, dairy and protein intake, and the risk of gout in men. $N$ Engl J Med. 2004;350(11):1093-1103.

7. Krishnan E. Chronic kidney disease and the risk of incident gout among middle-aged men: a seven-year prospective observational study. Arthritis Rheum. 2013;65(12):3271-3278.
8. Feig DI, Kang DH, Johnson RJ. Uric acid and cardiovascular risk. $N$ Engl J Med. 2008;359(17):1811-1821.

9. Singh JA. When gout goes to the heart: does gout equal a cardiovascular disease risk factor? Ann Rheum Dis. 2015;74(4):631-634.

10. Becker MA. Clinical aspects of monosodium urate monohydrate crystal deposition disease (gout). Rheum Dis Clin North Am. 1988;14(2):377-394.

11. Fam AG. Gout in the elderly. Clinical presentation and treatment. Drugs Aging. 1998;13(3):229-243.

12. Khanna D, Khanna PP, Fitzgerald JD, et al. 2012 American College of Rheumatology guidelines for management of gout. Part 2: therapy and antiinflammatory prophylaxis of acute gouty arthritis. Arthritis Care Res. 2012;64(10):1447-1461.

13. Emmerson BT. The management of gout. $N$ Engl J Med. 1996;334(7): 445-451.

14. Wallace SL, Singer JZ. Therapy in gout. Rheum Dis Clin North Am. 1988;14(2):441-457.

15. Ehrich EW, Dallob A, de Lepeleire I, et al. Characterization of rofecoxib as a cyclooxygenase- 2 isoform inhibitor and demonstration of analgesia in the dental pain model. Clin Pharmacol Ther. 1999;65(3): 336-347.

16. Ehrich EW, Schnitzer TJ, McIlwain H, et al. Effect of specific COX-2 inhibition in osteoarthritis of the knee: a 6 week double blind, placebo controlled pilot study of rofecoxib. Rofecoxib Osteoarthritis Pilot Study Group. J Rheumatol. 1999;26(11):2438-2447.

17. Langman MJ, Jensen DM, Watson DJ, et al. Adverse upper gastrointestinal effects of rofecoxib compared with NSAIDs. JAMA. 1999;282(20):1929-1933.

18. Simon LS, Weaver AL, Graham DY, et al. Anti-inflammatory and upper gastrointestinal effects of celecoxib in rheumatoid arthritis: a randomized controlled trial. JAMA. 1999;282(20):1921-1928.

19. Dogné JM, Supuran CT, Pratico D. Adverse cardiovascular effects of the coxibs. J Med Chem. 2005;48(7):2251-2257.

20. Mitchell JA, Akarasereenont P, Thiemermann C, Flower RJ, Vane JR. Selectivity of nonsteroidal antiinflammatory drugs as inhibitors of constitutive and inducible cyclooxygenase. Proc Natl Acad Sci US A. 1993;90(24):11693-11697.

21. Hozo SP, Djulbegovic B, Hozo I. Estimating the mean and variance from the median, range, and the size of a sample. BMC Med Res Methodol. 2005;5:13.

22. Higgins JP, Thompson SG, Deeks JJ, Altman DG. Measuring inconsistency in meta-analyses. BMJ. 2003;327(7414):557-560.

23. Moher D, Liberati A, Tetzlaff J, Altman DG; PRISMA Group. Preferred reporting items for systematic reviews and meta-analyses: the PRISMA statement. BMJ. 2009;6(7):e1000097.

24. Li T, Chen SL, Dai Q, et al. Etoricoxib versus indometacin in the treatment of Chinese patients with acute gouty arthritis: a randomized double-blind trial. Chin Med J. 2013;126(10):1867-1871.

25. Rubin BR, Burton R, Navarra S, et al. Efficacy and safety profile of treatment with etoricoxib $120 \mathrm{mg}$ once daily compared with indomethacin $50 \mathrm{mg}$ three times daily in acute gout: a randomized controlled trial. Arthritis Rheum. 2004;50(2):598-606.

26. Schumacher HR, Boice JA, Daikh DI, et al. Randomised double blind trial of etoricoxib and indometacin in treatment of acute gouty arthritis. BMJ. 2002;324(7352):1488-1492.

27. Xu L, Liu S, Guan M, Xue Y. Comparison of prednisolone, etoricoxib, and indomethacin in treatment of acute gouty arthritis: an ppen-label, randomized, controlled trial. Med Sci Monit. 2016;22:810-817.

28. Dubois RN, Abramson SB, Crofford L, et al. Cyclooxygenase in biology and disease. Faseb J. 1998;12(12):1063-1073.

29. Cronstein BN, Terkeltaub R. The inflammatory process of gout and its treatment. Arthritis Res Ther. 2006;8(Suppl 1):S3.

30. Ricciotti E, Fitzgerald GA. Prostaglandins and inflammation. Arterioscler Thromb Vasc Biol. 2011;31(5):986-1000.

31. Schjerning Olsen AM, Fosbøl EL, Lindhardsen J, et al. Duration of treatment with nonsteroidal anti-inflammatory drugs and impact on risk of death and recurrent myocardial infarction in patients with prior myocardial infarction: a nationwide cohort study. Circulation. 2011;123(20):2226-2235. 
32. Smyth EM, Grosser T, Wang M, Yu Y, Fitzgerald GA. Prostanoids in health and disease. J Lipid Res. 2009;50(Suppl):S423-S428.

33. Patrignani P, Tacconelli S, Bruno A, Sostres C, Lanas A. Managing the adverse effects of nonsteroidal anti-inflammatory drugs. Expert Rev Clin Pharmacol. 2011;4(5):605-621.

34. Ma L, Elliott SN, Cirino G, Buret A, Ignarro LJ, Wallace JL. Platelets modulate gastric ulcer healing: role of endostatin and vascular endothelial growth factor release. Proc Natl Acad Sci U SA. 2001;98(11):6470-6475.

35. Tarnawski A, Szabo IL, Husain SS, Soreghan B. Regeneration of gastric mucosa during ulcer healing is triggered by growth factors and signal transduction pathways. J Physiol Paris. 2001;95(1-6):337-344.

36. Fitzgerald GA. COX-2 and beyond: Approaches to prostaglandin inhibition in human disease. Nat Rev Drug Discov. 2003;2(11):879-890.

37. Tanaka A, Araki H, Komoike Y, Hase S, Takeuchi K. Inhibition of both COX-1 and COX-2 is required for development of gastric damage in response to nonsteroidal antiinflammatory drugs. J Physiol Paris. 2001;95(1-6):21-27.

38. Lichtenberger LM. Where is the evidence that cyclooxygenase inhibition is the primary cause of nonsteroidal anti-inflammatory drug (NSAID)induced gastrointestinal injury? Topical injury revisited. Biochem Pharmacol. 2001;61(6):631-637.

39. Gana TJ, Huhlewych R, Koo J. Focal gastric mucosal blood flow in aspirin-induced ulceration. Ann Surg. 1987;205(4):399-403.

40. Wallace JL, Cirino G. The development of gastrointestinal-sparing nonsteroidal anti-inflammatory drugs. Trends Pharmacol Sci. 1994;15(11):405-406.

41. Wallace JL, McKnight W, Reuter BK, Vergnolle N. NSAID-induced gastric damage in rats: requirement for inhibition of both cyclooxygenase 1 and 2. Gastroenterology. 2000;119(3):706-714.

42. Lanas A, Scheiman J. Low-dose aspirin and upper gastrointestinal damage: epidemiology, prevention and treatment. Curr Med Res Opin. 2007;23(1):163-173.
43. Lanas A, Perez-Aisa MA, Feu F, et al. A nationwide study of mortality associated with hospital admission due to severe gastrointestinal events and those associated with nonsteroidal antiinflammatory drug use. $\mathrm{Am}$ J Gastroenterol. 2005;100(8):1685-1693.

44. Cryer B. NSAID-associated deaths: the rise and fall of NSAIDassociated GI mortality. Am J Gastroenterol. 2005;100(8):1694-1695.

45. Lanas A, García-Rodríguez LA, Arroyo MT, et al. Risk of upper gastrointestinal ulcer bleeding associated with selective cyclo-oxygenase-2 inhibitors, traditional non-aspirin non-steroidal anti-inflammatory drugs, aspirin and combinations. Gut. 2006;55(12):1731-1738.

46. Asako H, Kubes P, Wallace J, Gaginella T, Wolf RE, Granger DN. Indomethacin-induced leukocyte adhesion in mesenteric venules: role of lipoxygenase products. Am J Physiol. 1992;262(5 Pt 1): G903-G908.

47. Asako H, Kubes P, Wallace J, Wolf RE, Granger DN. Modulation of leukocyte adhesion in rat mesenteric venules by aspirin and salicylate. Gastroenterology. 1992;103(1):146-152.

48. Cronstein BN, Sunkureddi P. Mechanistic aspects of inflammation and clinical management of inflammation in acute gouty arthritis. $J$ Clin Rheumatol. 2013;19(1):1-29.

49. van Durme CM, Wechalekar MD, Buchbinder R, Schlesinger N, van der Heijde D, Landewé RB. Non-steroidal anti-inflammatory drugs for acute gout. Cochrane Database Syst Rev. 2014 (9):CD010120.

50. Zhang S, Zhang Y, Liu P, Zhang W, Ma JL, Wang J. Efficacy and safety of etoricoxib compared with NSAIDs in acute gout: a systematic review and a meta-analysis. Clin Rheumatol. 2016;35(1):151-158.

51. Sterne JA, Sutton AJ, Ioannidis JP, et al. Recommendations for examining and interpreting funnel plot asymmetry in meta-analyses of randomised controlled trials. $B M J$. 2011;343:d4002.
Journal of Pain Research

\section{Publish your work in this journal}

The Journal of Pain Research is an international, peer reviewed, open access, online journal that welcomes laboratory and clinical findings in the fields of pain research and the prevention and management of pain. Original research, reviews, symposium reports, hypothesis formation and commentaries are all considered for publication

\section{Dovepress}

The manuscript management system is completely online and includes a very quick and fair peer-review system, which is all easy to use. Visit http://www.dovepress.com/testimonials.php to read real quotes from published authors. 